IdeAs

Idées d'Amériques

$17 \mid 2021$

Villes et culture dans les Amériques

\title{
Cidades e culturas nas Américas
}

Cidades entre o "capitalismo" cultural e as práticas culturais dos

habitantes

\section{Diana Burgos-Vigna e Cynthia Ghorra-Gobin}

Tradutor: Isabel Moraes

\section{OpenEdition}

Journals

\section{Edição electrónica}

URL: https://journals.openedition.org/ideas/11215

DOI: 10.4000/ideas. 11215

ISSN: 1950-5701

\section{Editora}

Institut des Amériques

\section{Refêrencia eletrónica}

Diana Burgos-Vigna e Cynthia Ghorra-Gobin, «Cidades e culturas nas Américas», IdeAs [Online], 17 |

2021, posto online no dia 01 maio 2021, consultado o 04 junho 2021. URL: http://

journals.openedition.org/ideas/11215 ; DOI: https://doi.org/10.4000/ideas.11215

Este documento foi criado de forma automática no dia 4 junho 2021.

\section{cc) (†) $९$}

IdeAs - Idées d'Amériques est mis à disposition selon les termes de la licence Creative Commons Attribution - Pas d'Utilisation Commerciale - Pas de Modification 4.0 International. 


\title{
Cidades e culturas nas Américas
}

\author{
Cidades entre o "capitalismo" cultural e as práticas culturais dos \\ habitantes
}

\author{
Diana Burgos-Vigna e Cynthia Ghorra-Gobin
}

Tradução : Isabel Moraes

1 Na tradição ocidental, a cultura é um dos principais atributos da cidade (Benevolo L., 1983). Ela molda a cidade por meio de construções de valor estético e histórico, inserindo-a em uma rede de ruas e avenidas que por sua vez dão lugar ao tráfego e à mobilidade, proporcionando, por vezes, belas paisagens, bem como locais para caminhadas e encontros. A cultura também é moldada pela cidade na medida em que sua monumentalidade e configuração contribuem para a constituição de estilos de vida urbanos, rituais, práticas e mentalidades.

2 No contexto contemporâneo de pós-revolução digital marcado pela mundialização e pela globalização ${ }^{1}$, as cidades continuam a se transformar a fim de participarem dos fluxos culturais e econômicos ao redor do mundo. De acordo com o filósofo Olivier Mongin (2013), trata-se da "cidade dos fluxos", que contribui para a circulação de ideias, informações, pessoas e práticas culturais, acolhendo grandes projetos urbanos, eventos culturais internacionais ou simplesmente a transformação de espaços públicos de bairros em transição. As mudanças não dizem respeito apenas às cidades globais (Sassen S., 1996) ou principais, elas também afetam as cidades secundárias (Hodos J., 2015), que fazem parte da globalização sem exercer um papel determinante na economia. Dessa forma, a cultura pode ser mobilizada de maneira a garantir a atratividade da cidade para investidores, empresários, classes criativas e turistas. Ela integra uma nova fase do capitalismo definida como capitalismo cultural (Harvey D., 2014).

3 Nas Américas, os fluxos migratórios também transformam as cidades. Há duas décadas, pesquisadores anglo-americanos vêm discutindo mudanças (pinturas murais, novos usos dos espaços públicos) após a chegada de populações oriundas da América Latina: o sociólogo Mike Davis (2000) se apoia em Urbanismo Mágico para descrever a reinvenção das cidades nos Estados Unidos conduzida pelos latinos. Mais recentemente, o historiador Andrew K. Sandoval-Strausz (2019) considera os latinos como imigrantes 
que teriam salvado as cidades nos Estados Unidos, como aponta sua análise em Barrio America. Em outras palavras, as práticas culturais dos latinos e a valorização dos espaços públicos por meio de murais ou do street art que eles realizam teriam um efeito regenerador para a cidade. Trata-se de um movimento de tipo bottom-up, iniciado pelos próprios atores sociais (habitantes ou artistas), bem diferente das políticas top-down que instrumentalizam a cultura visando uma estratégia de atratividade. São esses dois movimentos que a presente edição de IdeAs se propõe a apresentar e explorar: a cultura em prol de uma política de city branding que se manifesta através de reorganizações urbanas e eventos internacionais, e a cultura como reflexo de uma mobilização social que favorece a construção de uma narrativa de cidade que passa a se afirmar por meio do registro de pluralidade cultural.

\section{A cultura instrumentalizada: a política de atratividade da cidade}

4 Pesquisas realizadas sobre as consequências culturais da mundialização e da globalização destacaram inicialmente os riscos da influência do modelo americano sobre as culturas nacionais e urbanas. Dessa forma, fala-se dos riscos de uma americanização cultural do mundo (Guéhenno J-M., 1999; Tournès L., 2020). Entretanto, tal abordagem é criticada por pesquisadores que, influenciados pelos Cultural Studies, não compartilham do mesmo ponto de vista e consideram que a mundialização torna a diversidade cultural visível tanto na dimensão das cidades quanto em escala global. 0 antropólogo Arjun Appadurai, da Universidade de Chicago, destacou o princípio da diversidade cultural como resultado do fenômeno da migração associado à obra da imaginação ${ }^{2}$. Mas é sem dúvida o trabalho do economista e geógrafo Richard Florida intitulado The Rise of the Creative Class (2002) o de a maior influência sobre os atores urbanos (políticos e econômicos).

5 Florida observa o surgimento de uma nova classe social que ele chama de "classe criativa" devido a sua inventividade em campos tão variados como as artes, as finanças, a mídia, a alta tecnologia e outros setores. A classe criativa opta por se estabelecer em cidades que, por um lado, transmitem uma cultura de tolerância (TolerânciaTecnologia-Talento) em relação à diversidade cultural e, por outro lado, apresentam uma oferta cultural de qualidade. As comodidades culturais urbanas seriam, portanto, um fator de atratividade. A tese do pesquisador influenciou muito os tomadores de decisão locais que, preocupados em garantir a posição da cidade nos fluxos da mundialização e da globalização, têm conduzido políticas culturais ousadas que resultaram na valorização do patrimônio histórico, na abertura de novas salas de shows e espetáculos, de novos museus ou na reformulação de museus antigos, na organização de feiras e eventos, bem como em grandes projetos urbanos, como o planejamento de bairros residenciais ecológicos. Nesse sentido, a política cultural faz parte de uma estratégia de atratividade que visa atender às demandas das classes criativas, dos investidores e dos turistas. Em sua análise, Florida não dá ênfase aos turistas, ao contrário dos tomadores de decisão que lhes conferem um lugar considerável.

6 No contexto contemporâneo de desenvolvimento econômico baseado no conhecimento (knowledge-based economy), a política urbana é inseparável da política cultural (Landry C., 2008). Essa tese representa um avanço na medida em que a cultura é valorizada. Contudo, a instrumentalização da cultura em prol de uma estratégia de atratividade 
também representa o risco de exclusão de uma parte da população, a saber, as classes trabalhadoras, além de desencadear processos de gentrificação que beneficiam setores da população ricos e conectados.

\section{Cultura, práticas dos habitantes e direito à cidade}

7 Outra maneira de abordar a questão da cultura na cidade é partindo do nível microlocal, com o enfoque de observação das práticas culturais. É um ângulo que permite perceber a cultura não como um recurso político, econômico ou simbólico na escala da cidade, mas como um bem coletivo, ou mesmo como uma ferramenta de transformação e de empoderamento nas mãos dos habitantes. Esse tipo de análise se alinha à concepção de cidade como um espaço moldado por aqueles que a utilizam diariamente, por vezes transformando-a ou modificando seus usos. É o ponto de vista de Henri Lefebvre que, já nos anos 60 , definiu o direito à cidade como uma "forma superior dos direitos, enquanto direito à liberdade, à individualização na socialização, ao habitat e a habitação. $O$ direito à obra (atividade participante) e o direito à apropriação (bem distinto da propriedade) que se imbricam dentro do direito a cidade" (Lefebvre H., 1968: 140). Na mesma linha, teóricos da geografia radical, seguidos pelos da geografia crítica, denunciaram o desenvolvimento urbano que privilegia o valor de troca (comercial, imobiliário) em detrimento do valor de uso, ou seja, às custas da possibilidade de praticar a cidade, de realizar encontros e de expressar a liberdade individual ou coletiva (Brenner N., Marcuse P., Mayer M., 2012).

As teorias do direito à cidade influenciaram profundamente as reflexões sobre as políticas urbanas e o lugar da cultura nas Américas. os estudos urbanos na América Latina se apoderaram delas desde o início do século xxi, levando os debates para muito além do campo acadêmico (Burgos-Vigna D., 2020). Vários países retomaram então a noção, inserindo-a em textos constitucionais ${ }^{3}$ ou, a nível local, em cartas urbanas ${ }^{4}$. Declinado no campo cultural, o direito à cidade é um conceito que permite enfatizar as ideias de participação, de co-construção e de diversidade cultural. Os estudos decoloniais também o utilizam para criticar o domínio das culturas indígenas, afrodescendentes e mestiças, com frequência denegridas e invisibilizadas, tendo voz apenas através da folclorização de algumas de suas características consideradas consensuais (Quijano A., 2012).

9 Essas orientações se difundiram ainda mais rapidamente nos primeiros anos do século XXI, incentivadas por novas estratégias de organizações internacionais como o Banco Internacional de Desenvolvimento no campo das políticas urbanas (Rojas E., 2009) ou a UNESCO, no campo estritamente cultural (UNESCO, 2003; 2005). Sem descartar a perspectiva da cultura como recurso econômico importante, essas organizações deram maior ênfase à participação das populações na preservação de sua(s) cultura(s), na construção de narrativas de identidade, valorizando o patrimônio imaterial, se referindo a um patrimônio "vivo", à diversidade cultural e à sustentabilidade. Tais discursos estão especialmente ligados ao surgimento das "políticas de mejoramiento barrial" (políticas de melhoria de bairros) realizadas nos últimos anos nas cidades latino-americanas, em nível micro de bairros e ruas. São programas que integram uma visão da cultura como ferramenta de desenvolvimento social e urbano, e até mesmo como "o quarto pilar da sustentabilidade" (UCLG, 2010). 
10 Todavia, essas políticas nem sempre escapam dos riscos de instrumentalização ou de apropriação mencionados na primeira parte de nossa introdução. A arte de rua é um exemplo emblemático disso. Ainda que essa forma de arte seja definida sobretudo pelo seu caráter transgressivo ao tomar posse de espaços urbanos inicialmente não destinados a tal uso, ela não evita, no entanto, o risco de subversão ao se tornar uma forma estética, retomada pelas autoridades locais para valorizar certos bairros periféricos (Schacter R., 2014).

11 Deveríamos, portanto, descartar as culturas urbanas como formas de expressão autônomas no espaço público? Se arte e cultura fazem parte dos conflitos em torno dos espaços urbanos e permanecem no centro do jogo de interesses entre elites, autoridades locais e habitantes, o fato é que seu alcance democrático não deve ser subestimado. Dessa forma, Olivier Dabène vê a arte de rua como uma das vias de democratização possíveis em um contexto em que os meios tradicionais de participação estão saturados. Por meio do debate público e da consciência que ela propicia, inclusive por conta da emoção que ela inspira, esta forma de arte contribui para a renovação de nossas democracias (Dabène O., 2020). A questão democrática, quer seja enquanto "poder de agir" (Carrel M., 2013), quer seja no encontro diário com o Outro, se apresenta da mesma forma em todas as práticas culturais nas cidades das Américas: do teatro popular a exposições e espetáculos diversos, passando por parques culturais ou simplesmente no acesso a determinados espaços públicos. Como lembra o antropólogo Nestor García Canclini, a preservação dos bens culturais nunca deve prevalecer sobre a proteção das pessoas que precisam deles para viver (1999: 28). Através das práticas culturais, trata-se de passar da cidade para ser vista à a cidade para ser vivida, da cidade espetáculo ou da cidade-museu ao espaço urbano compartilhado.

\section{A convergência das questões levantadas nas cidades do Sul e do Norte}

12 Os artigos desta edição refletem sobre o lugar da cultura nas cidades das Américas. Alguns destacam as tensões entre a cultura tal como ela é percebida pelas elites (econômica e política) e a percepção dos habitantes, enquanto outros autores ressaltam a riqueza e a criatividade da vida urbana através da cultura. Eles respondem a questões que dizem respeito tanto à política cultural local quanto à vida cotidiana dos habitantes:

- De que maneira certos espaços culturais podem se tornar lugares de contestação e resistência em contextos de crise política? Mélanie Toulhoat apresenta o Salão Internacional de Humor de Piracicaba como um rico observatório da política cultural durante a transição democrática brasileira, tanto enquanto reflexo local do desenvolvimento nacional quanto como redoma de liberdade em um contexto repressivo. A questão da mobilização e contestação também é explorada por Lucía Durán, que se debruça sobre a cidade de Quito, onde, em tempos de crise, o patrimônio se torna uma fonte de conflito, mas também de novas apropriações. A pandemia levanta igualmente a questão de uma cidade espetáculo sem espectadores.

- Que ligações são forjadas entre a obra espetáculo urbano e o(s) público(s)? Como as obras culturais escolhidas por autoridades eleitas podem dar origem a polêmicas, ou ainda a conflitos enraizados em problemáticas sociais? O artigo de Suzanne Paquet e Laurent Vernet analisa a controvérsia em torno da recepção da obra La vélocité des lieux em 
Montréal-Nord e a explica através da dificuldade em definir o seu público. A análise inclui tanto patrocinadores como artistas em busca de projeção urbana, bem como um público local estranho a esse tipo de arte pública.

- Como o fomento de certas práticas culturais retomadas pelo poder político pode contribuir para reconfigurar os próprios espaços urbanos? Pascale Nédélec analisa assim a transformação da área turística de Las Vegas, que continua sendo moldada pelos carrosem prol de turistas-pedestres. A questão da transformação dos espaços urbanos também é levantada pelo artigo de Catherine Paquette e Luis Campos Medina, que observam os efeitos de programas culturais realizados por autoridades locais ou nacionais em várias cidades latino-americanas. Esse trabalho lhes permite estabelecer uma tipologia que leva em conta o impacto no espaço público e no tecido social dos bairros em questão.

- A cultura teria se tornado parte integrante do capitalismo contemporâneo, às vezes definido como "capitalismo cognitivo", como exprimem os geógrafos de inspiração marxista? Esta é a hipótese de Simon Renoir ao estudar a revitalização por atores privados do centro de Detroit, uma cidade emblemática do declínio demográfico e econômico. Sem dúvida, a performance discursiva da cultura levou a uma reconfiguração social e espacial da cidade, mas também levou à invisibilização das práticas culturais em torno da arte de rua nos bairros periféricos da cidade. $O$ tema da arte de rua também é abordado por Aline Hémond em seu trabalho sobre Chicago, no qual ela demonstra que o processo de apropriação de espaços públicos pelos latinos resultou em uma gentrificação do bairro de Pilsen e em um certo apelo turístico, o que é problemático para os habitantes.

- De que forma o objetivo de desenvolver o turismo em uma cidade pequena dos Estados Unidos desqualifica a presença de populações indígenas relegadas à periferia urbana? Céline Planchou e Sandrine Baudry discutem as contradições das autoridades públicas de Rapid City (Dakota) que, por um lado, reivindicam um passado histórico indígena e, por outro, negam a presença indígena no centro turístico da cidade.

- As práticas culturais também são alavancas de empoderamento, e, em alguns casos, representam o acesso à cidadania local. Esses são pontos explorados em vários artigos de nossa atual edição. Um exemplo é o trabalho de Fanny Arnulf sobre o teatro nas favelas.

- De que maneira a cultura contribui para o senso de pertencimento a uma comunidade? Barbara Morovich, em seu estudo sobre os bairros do sul de Buenos Aires, e Baptiste Mongis a respeito das cidades bolivianas de La Paz e El Alto, também mostram como as políticas urbanas conduzidas pelas autoridades produzem várias interações com os habitantes, entre tensões e negociações.

13 A escolha dessas cidades das Américas não se deve a seu caráter excepcional ou exemplar. A maioria delas são “cidades comuns" (Robinson J., 2006). Sua apresentação cruzada nos permite evitar categorizações e hierarquizações frequentes e por vezes enganosas, tais como cidades do Sul ou cidades do Norte, cidades da América Latina ou cidades anglo-americanas, cidades em desenvolvimento ou cidades ricas. Referir-se à cultura significa afirmar que a cidade permanece como "o lugar de encontro com o outro" (Barthes R., 2001), e também significa destacar, para cada um dos casos apresentados, o que torna os lugares singulares, às vezes conflitantes, mas onde uma infinidade de experiências urbanas podem ser expressadas. 


\section{BIBLIOGRAFIA}

Appadurai, Arjun, Après le colonialisme : les conséquences culturelles de la mondialisation, Paris, Payot, 2015.

Barthes, Roland, L'aventure sémiologique, Paris, Seuil, 1991.

Benevolo, Leonardo, Histoire de la ville, Fribourg, Éditions Parenthèses, 1983.

Bourdieu, Pierre, La Distinction. Critique sociale du jugement, Paris, Ed. de Minuit, coll. Le Sens Commun, 1979.

Brenner Neil, Marcuse, Peter et Mayer, Margit, Cities for People, Not for Profit: Critical Urban Theory and the Right to the City, New York et Londres, Routledge, 2012.

Burgos-Vigna, Diana, « Le droit à la ville et ses passages transatlantiques », Revue Pandora, Université Paris 8, $n^{\circ}$ 15, 2020, p.141-154, https://etudes-romanes.univ-paris8.fr/IMG/pdf/ pandora15_interactif.pdf, page consultée le 12 février 2021.

Darchen, Sébastien \& Diane-Gabrielle, Tremblay, « La thèse de la classe créative : son incidence sur l'analyse des facteurs d'attraction et de la compétitivité urbaine », Revue Interventions Économiques/Papers in Political Economy n 37, 2008,

https://journals.openedition.org/interventionseconomiques/503, page consultée le 11/01/2021.

Carrel, Marion, Faire participer les habitants? Citoyenneté et pouvoir d'agir dans les quartiers populaires, Lyon, ENS éditions, 2013.

CGLU (Ciudades y Gobiernos Locales Unidos), La cultura es el cuarto pilar del desarrollo sostenible, $3^{\mathrm{e}}$ Congrès Mondial, México, 2010.

Ghorra-Gobin, Cynthia (dir.), Dictionnaire critique de la mondialisation, Paris, Armand Colin, 2012.

Dabène, Olivier, Street Art and Democracy in Latin America, Londres, Palgrave Macmillan, 2020.

Davis, Mike, Magical Urbanism, Londres, New York, Verso, 2000.

Florida, Richard, The Creative Class: And How It's Transforming Work, Leisure, Community and Everyday Life, New York, Basic Books, 2002.

García Canclini, Néstor, « Los usos sociales del patrimonio cultural », in Ernesto Aguilar (dir.), Patrimonio Etnológico. Nuevas perspectivas de estudio, Consejería de Cultura-Junta de Andalucía, 1999, p. 16-33.

Guehenno, Jean-Marie, « Américanisation du monde ou mondialisation de l'Amérique », Politique étrangère, 1999, 64-1, p. 7-20.

Harvey, David, « Vers la ville entrepreneuriale. Mutation du capitalisme et transformations de la gouvernance urbaine ", in Cécile Gintrac et Mathieu Giroud (dir.), Villes contestées, Ed. Les prairies ordinaires, 2014, p. 125.

Hodos, Jerome, " Globalization and the Concept of the Second City ", City \& Community, vol. 6 \#4, 315-333, 2007, https://journals.sagepub.com/doi/full/10.1111/j.1540-6040.2007.00230.x, page consultée le $21 / 12 / 2020$.

Jacobs, Jane, Death and Life of the American City, New York, Random House USA Inc., 1961.

Quijano, Anibal, «Bien Vivir : entre el desarrollo y la des/colonialidad del poder », Viento Sur, $\mathrm{n}^{\circ} 122,2012$, p. 46-56. 
Landry, Charles, The Creative City, New York, Londres, Routledge, 2008.

Lefebvre, Henri, Le Droit à la Ville, Paris, Anthropos, Ed. 2009 (1 1 ère édition en 1967)

Mongin, Olivier, La ville des flux, Paris, Fayard, 2013.

Robinson, Jennifer, «Villes ordinaires : vers des études urbaines post-coloniales », in Cécile Gintrac et Mathieu Giroud (dir.), Villes contestées, Paris, Les Prairies Ordinaires, 2014 (traduction d'un texte de 2006), p. 35-55.

Rojas, Eduardo (dir.), Construir Ciudades, mejoramiento de barros y calidad de vida urbana, Washington DC, BID, 2009.

Sandoval-Strauz, Andrea K., Barrio America, Basic Books, 2019.

Sassen, Saskia, La ville globale. New York, Londres, Tokyo, Paris, Descartes \& Cie, 1996.

Schacter, Rafael, « The ugly truth: Street art, Graffiti and the Creative city », Art and The Public Sphere, vol. 3, n² 2, 2014, p. 161-176.

Supiot, Alain, Mondialisation ou globalisation? Les leçons de Simone Weil, Paris, Collège de France, coll. « Conférences », 2019.

Tournès, Ludovic, Américanisation. Une histoire mondiale. XVIII ${ }^{e}-\mathrm{XXI}^{e}$ siècles, Paris, Fayard, coll.

"L'épreuve de l'histoire », 2020.

UNESCO, Convention pour la Sauvegarde du patrimoine culturel immatériel, Paris, 17 octobre 2003.

UNESCO, Convention sur la protection et la promotion de la diversité des expressions culturelles, Paris, 20 octobre 2005.

\section{NOTAS}

1. Seguindo o Dicionário Crítico da Globalização (Ghorra-Gobin C., 2012) e o trabalho de Alain Supiot (2019), o artigo distingue mundialização, que corresponde à intensificação das trocas e relações em escala global, de globalização, que se refere à circulação de capital, à financeirização do capitalismo e à política neoliberal.

2. Seu livro de 1996, Modernity at Large: the Cultural dimensions of Globalization, foi traduzido para o português em 2002 pela Teorema em 2004: Dimensões culturais da globalização. A modernidade sem peias.

3. Brasil em 2001, Equador em 2008.

4. Carta Mundial pelo Direito à Cidade (Quito, 2004), Carta da Cidade do México pelo Direito à Cidade (2010).

\section{AUTORES}

\section{DIANA BURGOS-VIGNA}

Diana Burgos-Vigna est professeure en études latino-américaines à l'Université Paris Nanterre et membre du laboratoire CRIIA où elle est responsable du GRECUN (Groupe État Culture Nation 
dans le monde ibéro-américain). Ses recherches portent principalement sur les villes sudaméricaines et s'articulent autour de trois axes principaux : la démocratie participative, les réseaux de villes, et les politiques culturelles et patrimoniales locales.

\section{CYNTHIA GHORRA-GOBIN}

Cynthia Ghorra-Gobin CNRS-Iheal, Université Sorbonne Nouvelle, est géographe et membre du laboratoire CREDA (Centre de recherche et de documentation des Amériques). Ses recherches qui portent principalement sur les villes nord-américaines sont centrées sur les transformations spatiales et culturelles de la ville en relation avec la mondialisation et la globalisation. Elle a coordonné les deux éditions du Dictionnaire critique de la mondialisation, Armand Colin, 2006 et 2012 . 